\title{
Impact of Standardization of Creatinine Methodology on the Assessment of Glomerular Filtration Rate in Children
}

\author{
TARAK SRIVASTAVA, URI S. ALON, RANDAH ALTHAHABI, AND UTTAM GARG \\ Section of Nephrology [T.S., U.S.A.], Department of Pathology and Laboratory Medicine [R.A., U.G.], University of Missouri at Kansas \\ City, Kansas City, MO 64108
}

\begin{abstract}
There is a global effort to standardize clinical laboratory serum creatinine measurements to the reference method of isotope-dilution mass spectrometry (IDMS). Creatinine values in serum and urine are frequently used in children to calculate creatinine clearance $(\mathrm{mCrCl})$ or estimate glomerular filtration rate (GFR) by Schwartz's equation (eGFR). The original normative data of $\mathrm{mCrCl}$ and eGFR were developed using Jaffe method. To investigate what impact the differences in methodologies of creatinine analysis will have on $\mathrm{mCrCl}$ and eGFR, we measured creatinine in random serum and urine samples by three commercially available assays: Jaffe (J), enzymatic (E) and enzymatic method traceable to IDMS (E-IDMS). There was a significant bias in the two enzymatic methods when compared with $\mathrm{J}$ method. The theoretical predicted errors in overestimating $\mathrm{mCrCl}$ ranged from 1.10 to 1.34 by $\mathrm{E}$ and 1.20 to 1.54 by E-IDMS; and in calculating eGFR $1.07-1.16$ by E and $1.30-1.46$ by E-IDMS, which was further confirmed in children who had formal GFR evaluation. Thus, as the clinical laboratories calibrate their creatinine assays to the gold standard IDMS method, it is important for the pediatric nephrology community to develop new equations for estimation of GFR based on the new creatinine assay. (Pediatr Res 65: 113-116, 2009)
\end{abstract}

$\mathrm{C}$ reatinine measurement in serum and urine has been used for decades to evaluate renal function in both adults and children. The gold standard isotope-dilution mass spectrometry (IDMS) method, for creatinine assay, is both expensive and cumbersome for routine use (1). On the laboratory side of patient care, the routine creatinine measurement in the past was performed using Jaffe method, which was known to have interference from chromogens $(1,2)$. The creatinine assays over the years have changed from the original Jaffe to kinetic Jaffe and then to enzymatic methods $(1,3)$. Currently, to provide more accurate results and uniformity among laboratories, the assays are being recalibrated by manufacturers to provide IDMS equivalent results for both kinetic Jaffe and enzymatic methods. On the clinical side of patient care, pediatricians have used the creatinine values to measure creatinine clearance $(\mathrm{mCrCl})$ and to estimate glomerular filtration rate (eGFR). The $\mathrm{mCrCl}$ and eGFR values are commonly used to modify drug dose based on renal function and to stratify severity of chronic kidney disease (CKD) from CKD stages 1 to 5. Furthermore, the guidelines for standardizing care in

Received April 24, 2008; accepted July 30, 2008

Correspondence: Tarak Srivastava, M.D., Section of Nephrology, The Children's Mercy Hospital, 2401 Gillham Road, Kansas City, MO 64108; e-mail: tsrivastava@cmh.edu Supported by the Sam and Helen Kaplan Research Fund in Pediatric Nephrology.
CKD, which have been developed by K-DOQI, are based on stratification of CKD into these five stages (4).

GFR is often estimated by predictive equations developed by multivariate regression analysis techniques using a definite method for GFR determination such as inulin clearance or iothalamate. The most commonly used equations are modification of diet in renal disease (MDRD) for adults and Schwartz's formula for children (5-7). Originally, these equations were developed using the kinetic Jaffe method to determine serum and urine creatinine. In 2007, the College of American Pathologists (CAP) survey of 5382 clinical laboratories showed that $\sim 80 \%$ of clinical laboratories are using modified Jaffe's and $\sim 20 \%$ enzymatic methods, respectively. The National Disease Education Program is recommending calibration of clinical laboratories creatinine assays to definitive reference method of IDMS (8). On the basis of these recommendations, the manufacturers for creatinine assays are recalibrating their methods to be traceable to IDMS method and currently $\sim 25 \%$ of laboratories have converted to an assay using IDMS traceable methods $(8,9)$. Thus, as the clinical laboratories start to make this transition, we investigated what impact the different creatinine assays being used in clinical laboratories will have on $\mathrm{mCrCl}$ and eGFR using Schwartz's formula.

\section{MATERIALS AND METHODS}

Creatinine in serum and urine was measured by the Jaffe's kinetic alkaline picrate method and by two enzymatic methods, both using Vitros chemistry analyzer (Ortho-Clinical Diagnostics, Rochester, NY). These two enzymatic methods use the same principle for creatinine measurement, but the more recent one was modified to be traceable to IDMS method. The three methods have within-run and between-run imprecision of $<5 \%$. In the following text, we abbreviate these creatinine methods as J (kinetic Jaffe's), E (traditional enzymatic), and E-IDMS (enzymatic method traceable to IDMS method). Random serum and urine samples coming to the laboratory for routine analysis were simultaneously analyzed by J, E, and E-IDMS creatinine assays on the same sample. The percent bias, slope, and intercept in creatinine measurement by $\mathrm{E}$ and $\mathrm{E}-\mathrm{IDMS}$ from $\mathrm{J}$ were determined. The potential theoretical overestimation in $\mathrm{mCrCl}$ and eGFR was calculated from the observed bias in random serum and urine assays. The theoretical overestimation in $\mathrm{mCrCl}$ was derived by taking the extremes for urine and serum. The lower limit was calculated using the lower limit for urine divided by the upper

\footnotetext{
Abbreviations: CKD, chronic kidney disease; DTPA-GFR, ${ }^{99 \mathrm{~m}}$ Tc-diethylene triamine penta-acetic acid scan for glomerular filtration rate; $\mathbf{E}$, creatinine assay by enzymatic method; eGFR, estimated glomerular filtration rate; E-IDMS, creatinine assay by enzymatic method traceable to IDMS; IDMS, isotope-dilution mass spectrometry; J, creatinine assay by Jaffe's method; $\mathbf{m C r C l}$, measured creatinine clearance; MDRD, modification of diet in renal disease
} 

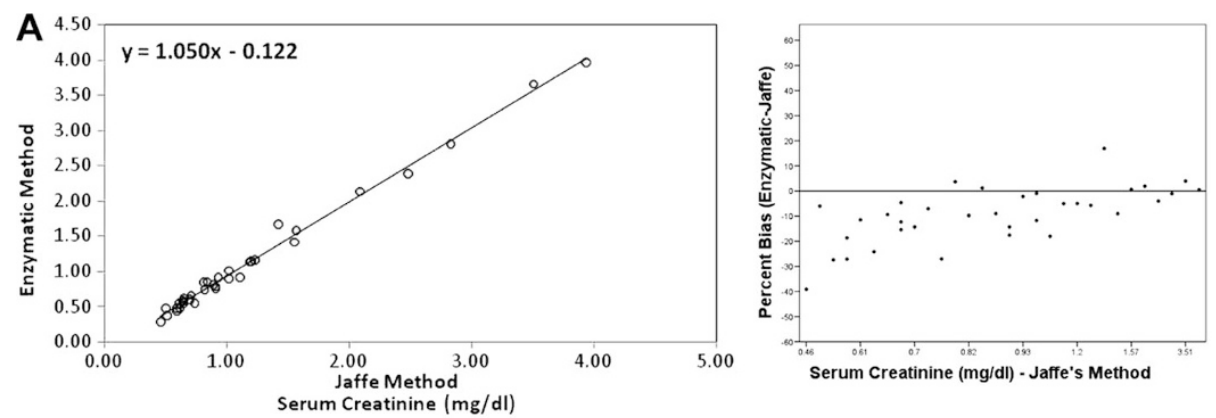

Figure 1. The scatter-plot and percent bias in creatinine analyzed by E (A) and E-IDMS (B) assays compared with $\mathrm{J}$ in 36 random serum samples. The scatter-plot shows the regression lines for E and E-IDMS assays compared with $\mathrm{J}$ with their respective regression equation showing the slope and intercept. The other panel shows the percent bias for serum creatinine for E and E-IDMS compared with J.
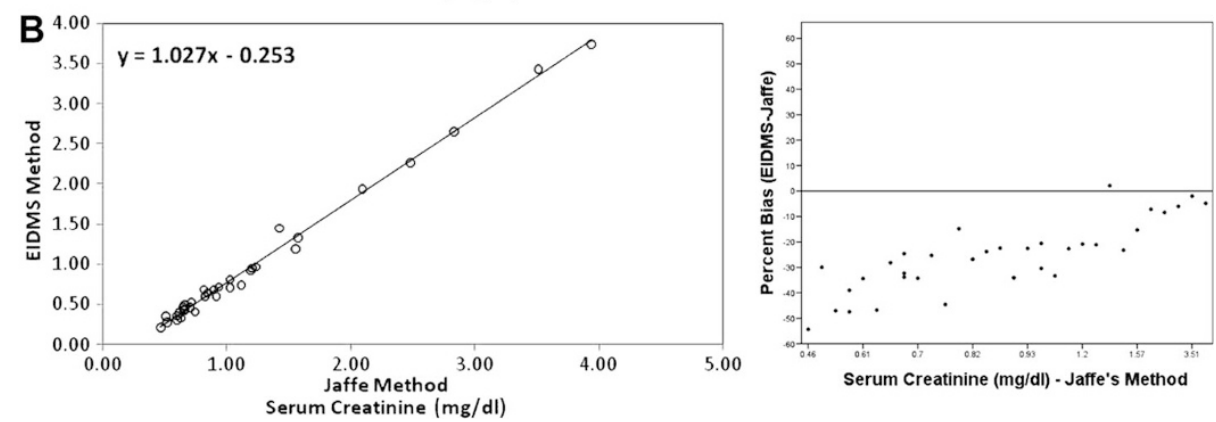

limit for serum. The upper limit was calculated using the upper limit for urine divided by the lower limit for serum. The magnitude of bias, and the slope and intercept was calculated using regression analysis using SPSS 15.0. The study was approved by institutional review board of Children's Mercy Hospital, University of Missouri at Kansas City.

In 18 children, nine of whom had $\mathrm{mCrCl}$ (group A) based on a timed urine collection and simultaneous serum analysis, and the other nine GFR determination by ${ }^{99 \mathrm{~m}} \mathrm{Tc}$-diethylene triamine penta-acetic acid (DTPA) scan (group $\mathrm{B})$, the $\mathrm{mCrCl}$ and eGFR were established using the three assays. The ${ }^{99 \mathrm{~m}}$ Tc-diethylene triamine penta-acetic acid scan for GFR (DTPA-GFR) was derived using the plasma disappearance curve after a single injection with 55 $\mu \mathrm{Ci} / \mathrm{kg}$ (maximum $10 \mathrm{mCi}$ ) of ${ }^{99 \mathrm{~m}} \mathrm{Tc}-\mathrm{DTPA}$ and assessing radionuclide activity at 90,120, 150, and $180 \mathrm{~min}$. The eGFR was calculated using Schwartz formula: eGFR $=(k \times$ height $) /\left(S_{\mathrm{Cr}}\right)$ with age and gender appropriate ' $k$ ' value. The $\mathrm{mCrCl}$ was calculated using formula $\mathrm{mCrCl}=\left(U_{\mathrm{Cr}} \times \mathrm{V}\right) /\left(P_{\mathrm{Cr}}\right)$ corrected for body surface area. The overestimation in $\mathrm{mCrCl}$ and eGFR by $\mathrm{E}$ and E-IDMS compared with $\mathrm{J}$ was determined. The observed overestimation in $\mathrm{mCrCl}$ and eGFR was compared with the predicted overestimation calculated from random serum and urine samples.

\section{RESULTS}

Thirty-six random serum and 40 random urine samples were analyzed. The samples covered the range of serum creatinine from 0.2 to $5.0 \mathrm{mg} / \mathrm{dL}$ and urine creatinine from 3 to $273 \mathrm{mg} / \mathrm{dL}$ by Jaffe method. The serum creatinine value showed a significant decline as the assay was changed from $\mathbf{J}$ to $\mathrm{E}$ and then to E-IDMS. Mean $\pm \mathrm{SD}$ serum creatinine was by $\mathrm{J} 1.16 \pm 0.83 \mathrm{mg} / \mathrm{dL}$, by $\mathrm{E} 1.09 \pm 0.87 \mathrm{mg} / \mathrm{dL}(p<0.001)$, and by E-IDMS $0.94 \pm 0.85 \mathrm{mg} / \mathrm{dL}(p<0.001)$. In contrast, only minimal differences were noted in urine creatinine values by J $69.33 \pm 66.17 \mathrm{mg} / \mathrm{dL}$, by E $75.71 \pm 69.72 \mathrm{mg} / \mathrm{dL}(p<$ $0.001)$, and by E-IDMS $70.65 \pm 69.80 \mathrm{mg} / \mathrm{dL}(p=\mathrm{NS})$. The bias in serum creatinine was $-0.06 \pm 0.09$ by $\mathrm{E}$ and $-0.22 \pm$ 0.08 by E-IDMS compared with J. The regression line had a slope of 1.05 with an intercept of -0.122 for E, which means that there is a positive proportional bias of $5 \%$ based on the slope and a constant negative bias of -0.122 determined by the intercept of the regression line. Similarly, the slope was 1.03 with an intercept of -0.253 for E-IDMS. The bias in urine creatinine was $5.47 \pm 8.84$ by $\mathrm{E}$ and $1.95 \pm 8.93$ by
E-IDMS compared with J. The regression line had a slope of 1.06 with an intercept of 1.311 for $\mathrm{E}$ and a slope of 1.04 with an intercept of -0.813 for E-IDMS.

The scatter-plot and percent bias in random serum creatinine by $\mathrm{E}$ and $\mathrm{E}-\mathrm{IDMS}$ assays compared with $\mathrm{J}$ are shown in Figure 1. When $\mathrm{E}$ was compared with $\mathrm{J}$, the percent bias is larger at the lower serum creatinine values and seems mainly due to negative intercept, i.e. because of a constant bias. When $\mathrm{J}$ method was compared with E-IDMS, the differences were even larger.

Figure 2 shows the scatter-plot and percent bias in random urine creatinine by E and E-IDMS assays compared with J. On the basis of the random serum and urine samples, the theoretical predicted errors in overestimating $\mathrm{mCrCl}$ analyzed by $\mathrm{J}$ were $1.10-1.34$ by $\mathrm{E}$ and $1.20-1.54$ by E-IDMS; and in calculating eGFR $1.07-1.16$ by $\mathrm{E}$ and $1.30-1.46$ by E-IDMS.

To confirm the above-predicted overestimation values derived from random serum and urine samples, we measured serum and urine creatinine by the three methods in 18 children who had either formal $\mathrm{mCrCl}$ (group A, $n=9$ ) or DTPA-GFR (group $\mathrm{B}, n=9)$. The measured creatinine clearance $(\mathrm{mCrCl})$ and estimated GFR by Schwartz formula (eGFR), and the absolute difference (or bias) and the relative change (error) by three different assays are shown in Table 1. The observed overestimation for $\mathrm{mCrCl}$ in group $\mathrm{A}$ by $\mathrm{E}$ assay was 1.13 and by E-IDMS 1.26. The observed error for eGFR in group B by $\mathrm{E}$ assay was 1.11 and by E-IDMS 1.45. These values were similar for group A, when the eGFR was calculated using height and serum creatinine in these children (Table 1). In the nine children who had DTPA-GFR in group B, the eGFR was overestimated by $5 \%, 17 \%$, and $52 \%$ by J, E, and E-IDMS assays, respectively.

\section{DISCUSSION}

In 2003, to evaluate the accuracy and precision of serum creatinine assays, using fresh frozen serum, the CAP con- 

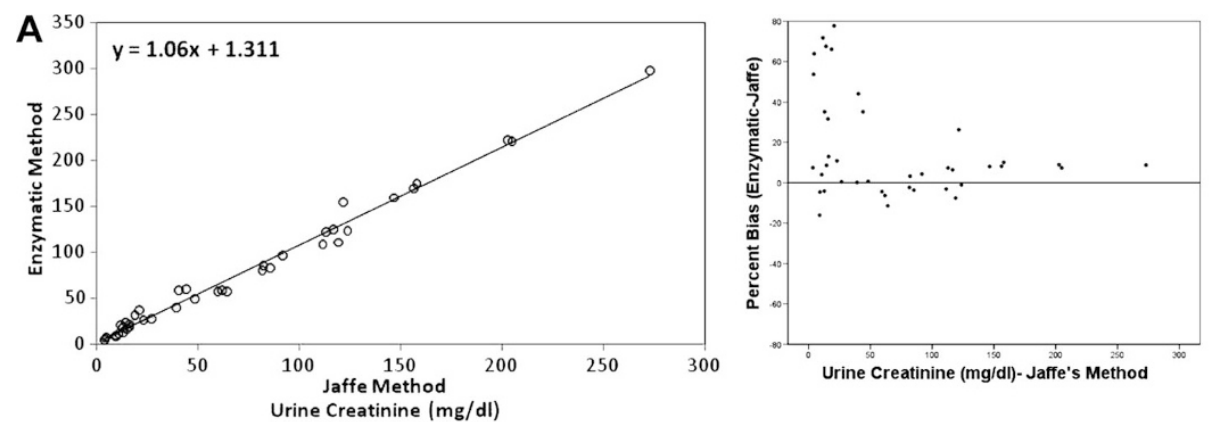

Figure 2. The scatter-plot and percent bias in creatinine analyzed by E (A) and E-IDMS (B) assays compared with $\mathrm{J}$ in 40 random urine samples. The scatter-plot shows the regression lines for E and E-IDMS assays compared with $\mathrm{J}$ with their respective regression equation showing the slope and intercept. The other panel shows the percent bias for urine creatinine for $\mathrm{E}$ and $\mathrm{E}$-IDMS compared with J.
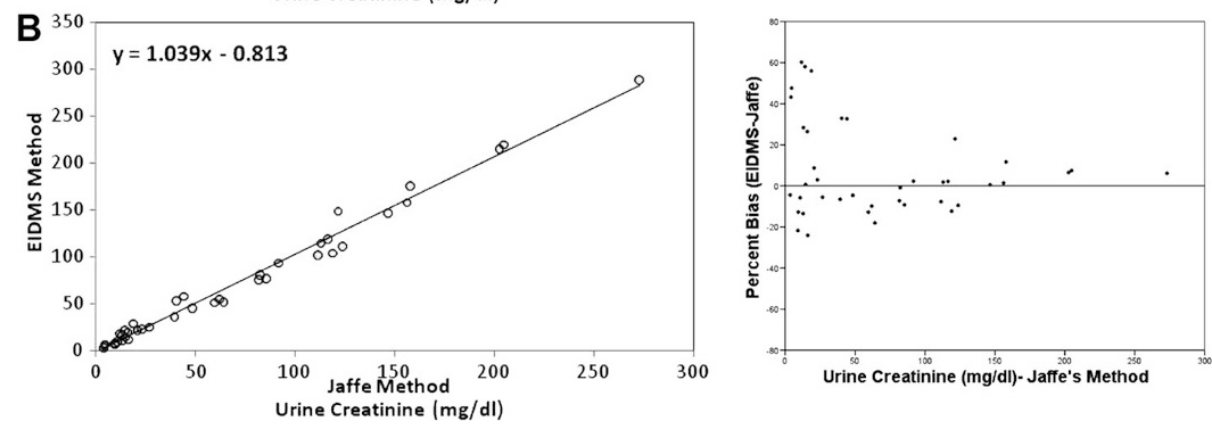

Table 1. The mean $\pm S D$ of measured creatinine clearance $(\mathrm{mCrCl})$ in nine children, and estimated glomerular filtration rate by Schwartz formula (eGFR) in nine other children who had DTPA-GFR

\begin{tabular}{|c|c|c|c|c|c|c|c|}
\hline & Jaffe & Enzymatic & E-IDMS & Enzymatic-Jaffe & E-IDMS-Jaffe & Enzymatic/Jaffe & E-IDMS/Jaffe \\
\hline \multicolumn{8}{|l|}{ Group A $(n=9)$} \\
\hline $\mathrm{mCrCl}\left(\mathrm{mL} / \mathrm{min} / 1.73 \mathrm{~m}^{2}\right)$ & $83.8 \pm 57.9$ & $94.1 \pm 64.1$ & $102.0 \pm 60.3$ & $10.3 \pm 9.1$ & $18.2 \pm 23.5$ & $1.13(1.05-1.22)$ & $1.26(1.09-1.44)$ \\
\hline $\mathrm{eGFR}\left(\mathrm{mL} / \mathrm{min} / 1.73 \mathrm{~m}^{2}\right)$ & $85.4 \pm 35.6$ & $98.9 \pm 46.4$ & $127.2 \pm 66.3$ & $13.5 \pm 13.7$ & $41.8 \pm 33.8$ & $1.12(1.04-1.21)$ & $1.41(1.29-1.55)$ \\
\hline \multicolumn{8}{|l|}{ Group B $(n=9)$} \\
\hline eGFR $\left(\mathrm{mL} / \mathrm{min} / 1.73 \mathrm{~m}^{2}\right)$ & $109.5 \pm 18.3$ & $123.1 \pm 27.1$ & $160.8 \pm 40.6$ & $13.6 \pm 13.7$ & $51.3 \pm 25.8$ & $1.11(1.03-1.20)$ & $1.45(1.32-1.58)$ \\
\hline
\end{tabular}

The absolute difference (or bias) and the relative change (error) as a ratio with its 95\% CI by three different assays: Jaffe's assay, enzymatic assay, and E-IDMS (enzymatic method traceable to IDMS) assay are shown. The DTPA-GFR for group B was $103.0 \pm 24.5 \mathrm{~mL} / \mathrm{min} / 1.73 \mathrm{~m}^{2}$.

ducted a proficiency testing survey of 5624 laboratories, which used 50 different instrument-method combinations. The creatinine results from these laboratories were compared with IDMS as the reference method. The study found that at a creatinine concentration of $0.9 \mathrm{mg} / \mathrm{dL}$ the surveyed creatinine methods were biased between -0.06 and $0.31 \mathrm{mg} / \mathrm{dL}(10)$. This could result in a potential error of up to $33 \%$ in calculating GFR. In the same study, the range of SD for a given instrument was as small as 0.04 to as large as 0.131 at a creatinine concentration of $0.90 \mathrm{mg} / \mathrm{dL}$, i.e. $5 \%-15 \%$. The study concluded that if maximal acceptable total error for calculated GFR was $15 \%$, and a method had interlaboratory SD of 0.06 , the maximum allowable calibration bias should be 0.034 at a creatinine concentration of $1.0 \mathrm{mg} / \mathrm{dL}$. Applying this clinical criterion, only $18 \%$ of the peer groups met the performance goal. Thus, there is a push to standardize creatinine to IDMS across all clinical laboratories.

GFR is often estimated by predictive equations, developed by multivariable regression techniques. The commonly used equations include MDRD equation for adults and Schwartz's formula for children (4). For these equations to be useful, creatinine values should be comparable to the methods, which were used to create the equations. A number of studies have shown that the currently used different creatinine assays have clinically significant differences from lack of standardization and presence of known interfering substances in serum and urine $(8,11,12)$. When we measured random urine and serum samples using three different commercially available assays, we found the discrepancy with assay methods to be true even more so for serum creatinine compared with urine. This is probably because of lower concentration of creatinine in serum compared with urine (13). The bias observed in urine creatinine was 1.31 (E) and -0.81 (E-IDMS) compared with $\mathrm{J}$, which is small given the large range of urine creatinine from 3 to $273 \mathrm{mg} / \mathrm{dL}$. These small differences can be attributed to other known interfering substances in random urine other than bilirubin, such as glucose, cephalosporin antibiotics, pyruvate, ascorbate, etc (1). Furthermore, most analytical methods for creatinine have higher imprecision at lower values, which may have contributed to these small differences observed by us in random urine samples. The lower serum creatinine values observed by us with E-IDMS assay had a similar negative intercept as reported by the manufacturer of the E-IDMS assay (http://www.orthoclinical.com/en-us/Pages/Home.aspx).

We found in our study that as the negative bias increased from the Jaffe method the overestimation in eGFR increased. Similar findings have been reported in adult population. In adult study, eGFR values using MDRD equation and IDMS method were significantly higher compared with traditional Jaffe method, especially in individuals with serum creatinine of $<1.75 \mathrm{mg} / \mathrm{dL}$ (14). The observed overestimation in eGFR from IDMS traceable creatinine assays is much less when the 
newer IDMS traceable MDRD equation is used (15). The original equations to estimate GFR from serum creatinine by Schwartz's group were performed on Technicon AutoAnalyzer in which the dialysate of $300 \mu \mathrm{L}$ of plasma or urine are subjected to the Jaffe creatinine chromogen reaction $(5,6)$. Although the newer laboratory methods such as E and E-IDMS may be more accurate and free from interferences compared with the older Jaffe method, they do introduce a source of error because of inherent difference between these methods. Although the results obtained from Jaffe's method is not synonymous with "true creatinine clearance," we have used this as our standard to compare the three methods as the original equations were developed using Jaffe's method. The differences, or biases, between the methods are generally higher at the lower serum creatinine values and, thus, contribute to larger inaccuracy in GFR at lower serum creatinine values (Fig. 1). In years past, when creatinine was measured by Jaffe method the serum creatinine was overestimated from interfering chromogens, which would not effect urinary creatinine measurement. This differential overestimation of serum over urine creatinine would have led to a systematic underestimation of $\mathrm{mCrCl}$, however by sheer coincidence, in healthy individuals this error is approximately similar to the difference between the $\mathrm{mCrCl}$ and GFR because of tubular secretion of creatinine (16). Now that the newer creatinine assay is free from interference from chromogens, it will lead to overestimation of $\mathrm{mCrCl}$. Indeed, the observed overestimation for $\mathrm{mCrCl}$ in group $\mathrm{A}$ by $\mathrm{E}$ assay was 1.13 (in agreement with the theoretical predicted value from random samples of $1.10-1.34$ ) and by E-IDMS 1.26 (predicted value 1.20-1.54). The observed value for eGFR in group B by E assay was 1.11 (predicted value was 1.07-1.16) and by E-IDMS 1.45 (predicted value 1.30-1.46). Thus, the $\mathrm{E}$ method gave higher $\mathrm{mCrCl}(13 \%)$ and eGFR (11\%) values compared with $\mathrm{J}$ method, and the difference was more marked for using the E-IDMS for $\mathrm{mCrCl}(26 \%)$ and eGFR (45\%).

The National Disease Education Program has made several recommendations for the improvement and development of creatinine assays. These recommendations include optimizing creatinine assays to provide accurate (traceable to IDMS) and precise measurements (8). The National Institute for Standards and Technology is in the process of developing a reference material at concentrations of approximately 0.80 and 4.00 $\mathrm{mg} / \mathrm{dL}$ to help manufacturers in standardization of creatinine assays for research and clinical use (8). In the mean time, it is recommended that laboratories indicate what method they are using and that clinicians will become familiar with them until universal standardization is complete. In 2007, the CAP survey showed $\sim 80 \%$ and $\sim 20 \%$ clinical laboratories using modified Jaffe's and enzymatic methods, respectively, and of which $\sim 25 \%$ of the laboratories have already converted to an assay using IDMS traceable methods (9). Thus, as the clinical laboratories continue to implement the recommended changes, this will have an important impact as how we use these creatinine values in clinical practice. Until the process of universal conversion to IDMS traceable method is com- plete, clinicians have to be aware of the methodology used by their clinical laboratory. Whereas the use of eGFR based on Schwartz's equation is permissible when using the Jaffe methodology as overestimation will occur if $\mathrm{E}$ and even more so if E-IDMS are used to analyze creatinine. In our present study, we provide the proof of concept, and because of the small sample of our study we do not recommend at this point to use the error factor we found (Table 1), but rather conduct further studies as has been performed in adults with MDRD equations.

We conclude that as standardization of measurement for serum and urine creatinine improve by utilization of the IDMS, greater deviation from true GFR occurs. Thus, new normative data for both $\mathrm{mCrCl}$ and even more so for eGFR will have to be developed, as continued use of old normative data may result in error in clinical care. In the transition time until the IDMS methodology becomes universal, clinicians should be well aware of the method used by their laboratory.

Acknowledgments. We are indebted for the laboratory assistance provided by Nancy Wilson, Patricia A Cudmore, Sylvia DiMaggio, and Nanci Burchell in Nuclear Medicine in completing the study.

\section{REFERENCES}

1. Peake M, Whiting M 2006 Measurement of serum creatinine-current status and future goals. Clin Biochem Rev 27:173-184

2. Rosano TG, Ambrose RT, Wu AH, Swift TA, Yadegari P 1990 Candidate reference method for determining creatinine in serum: method development and interlaboratory validation. Clin Chem 36:1951-1955

3. Srivastava T, Garg U, Chan YR, Alon US 2007 Essentials of laboratory medicine for the nephrology clinician. Pediatr Nephrol 22:170-182

4. National Kidney Foundation 2002 K/DOQI-clinical practice guidelines for chronic kidney disease: evaluation, classification, and stratification. Am J Kidney Dis 39:S1-S266

5. Schwartz GJ, Haycock GB, Edelmann CM Jr, Spitzer A 1976 A simple estimate of glomerular filtration rate in children derived from body length and plasma creatinine. Pediatrics 58:259-263

6. Schwartz GJ, Gauthier B 1985 A simple estimate of glomerular filtration rate in adolescent boys. J Pediatr 106:522-526

7. Levey AS, Bosch JP, Lewis JB, Greene T, Rogers N, Roth D 1999 A more accurate method to estimate glomerular filtration rate from serum creatinine: a new prediction equation. Modification of Diet in Renal Disease Study Group. Ann Intern Med 130:461-470

8. Myers GL, Miller WG, Coresh J, Fleming J, Greenberg N, Greene T, Hostetter T, Levey AS, Panteghini M, Welch M, Eckfeldt JH 2006 National Kidney Disease Education Program Laboratory Working Group: recommendations for improving serum creatinine measurement: a report from the Laboratory Working Group of the National Kidney Disease Education Program. Clin Chem 52:5-18

9. Chemistry/Therapeutic Drug Monitoring 2007 In: Participant Summary-College of American Pathology C-Survey. CAP, Northfield, IL pp 16-17

10. Miller WG, Myers GL, Ashwood ER, Killeen AA, Wang E, Thienpont LM, Siekmann L 2005 Creatinine measurement: state of the art in accuracy and interlaboratory harmonization. Arch Pathol Lab Med 129:297-304

11. Weber JA, van Zanten AP 1991 Interferences in current methods for measurements of creatinine. Clin Chem 37:695-700

12. Spencer K 1986 Analytical reviews in clinical biochemistry: the estimation of creatinine. Ann Clin Biochem 23:1-25

13. Coresh J, Astor BC, McQuillan G, Kusek J, Greene T, Van Lente F, Levey AS 2002 Calibration and random variation of the serum creatinine assay as critical elements of using equations to estimate glomerular filtration rate. Am J Kidney Dis 39:920-929

14. Chan MH, Ng KF, Szeto CC, Lit LC, Chow KM, Leung CB, Suen MW, Li PK, Lam CW 2004 Effect of a compensated Jaffe creatinine method on the estimation of glomerular filtration rate. Ann Clin Biochem 41:482-484

15. Vickery S, Stevens PE, Dalton RN, Van Lente F, Lamb EJ 2006 Does the ID-MS traceable MDRD equation work and is it suitable for use with compensated Jaffe and enzymatic creatinine assays? Nephrol Dial Transplant 21:2439-2445

16. Dalton NR, Haycock GB 1999 Laboratory investigation. In: Barratt TM, Avner ED, Harmon WE (eds) Pediatr Nephrol, 4th ed. Lippincott Williams \& Wilkins, Baltimore, pp 343-364 